\title{
Direct costs and cost-effectiveness of dual-source computed tomography and invasive coronary angiography in patients with an intermediate pretest likelihood for coronary artery disease
}

\author{
Marc Dorenkamp, ${ }^{1,2}$ Klaus Bonaventura, ${ }^{3,4}$ Christian Sohns, ${ }^{2}$ Christoph R Becker, ${ }^{5}$ \\ Alexander W Leber ${ }^{6}$
}

${ }^{1}$ Department of Cardiology, Charité-Universitätsmedizin Berlin, Campus Virchow-Klinikum, Berlin, Germany

${ }^{2}$ Department of Cardiology and Pneumology, Heart Center, Georg-August-University of Göttingen, Göttingen, Germany ${ }^{3}$ Department of Cardiology, Angiology, and Conservative Intensive Care, Klinikum Ernst von Bergmann, Potsdam, Germany

${ }^{4}$ University Outpatient Clinic Potsdam, Sports Medicine and Sports Orthopaedics, University of Potsdam, Potsdam, Germany ${ }^{5}$ Department of Clinical Radiology,

Ludwig-Maximilians-University Munich, Grosshadern Campus, Munich, Germany

${ }^{6}$ Department of Cardiology, Heart Center Bogenhausen, Städtisches Klinikum München, Munich, Germany

\section{Correspondence to} Dr Marc Dorenkamp, Department of Cardiology, Charité-Universitätsmedizin Berlin, Campus

Virchow-Klinikum,

Augustenburger Platz 1, 13553 Berlin, Germany;

marc.dorenkamp@charite.de

$\mathrm{MD}$ and $\mathrm{KB}$ contributed equally to this work.

Accepted 17 June 2011 Published Online First 16 August 2011

\begin{abstract}
Aims The study aims to determine the direct costs and comparative cost-effectiveness of latest-generation dualsource computed tomography (DSCT) and invasive coronary angiography for diagnosing coronary artery disease (CAD) in patients suspected of having this disease.

Methods The study was based on a previously elaborated cohort with an intermediate pretest likelihood for CAD and on complementary clinical data. Cost calculations were based on a detailed analysis of direct costs, and generally accepted accounting principles were applied. Based on Bayes' theorem, a mathematical model was used to compare the cost-effectiveness of both diagnostic approaches. Total costs included direct costs, induced costs and costs of complications.

Effectiveness was defined as the ability of a diagnostic test to accurately identify a patient with CAD.

Results Direct costs amounted to $€ 98.60$ for DSCT and to $€ 317.75$ for invasive coronary angiography. Analysis of model calculations indicated that cost-effectiveness grew hyperbolically with increasing prevalence of CAD. Given the prevalence of CAD in the study cohort (24\%), DSCT was found to be more cost-effective than invasive coronary angiography (€970 vs €1354 for one patient correctly diagnosed as having (AD). At a disease prevalence of $49 \%$, DSCT and invasive angiography were equally effective with costs of $€ 633$. Above a threshold value of disease prevalence of $55 \%$, proceeding directly to invasive coronary angiography was more costeffective than DSCT.
\end{abstract}

Conclusions With proper patient selection and consideration of disease prevalence, DSCT coronary angiography is cost-effective for diagnosing CAD in patients with an intermediate pretest likelihood for it. However, the range of eligible patients may be smaller than previously reported.

\section{INTRODUCTION}

Coronary artery disease (CAD) is the leading cause of death in the USA and Europe and can be considered as a major public health problem worldwide. ${ }^{1-3}$ The estimated total cost of CAD in Europe for 2008 is $€ 49$ billion. ${ }^{4}$ The significant social and economic impact of CAD makes its timely and efficient diagnosis a matter of the utmost importance. $^{5}$
Various imaging modalities have recently contributed to the improvement in detection of patients with suspected $\mathrm{CAD}^{6}{ }^{6}$ In particular, contrast-enhanced multi-detector computed tomography (MDCT) has emerged as a valuable non-invasive tool to evaluate coronary arteries. Cardiac MDCT has rapidly evolved from 4-row detector systems to latest-generation scanners including 320-row detector row systems and dualsource computed tomography (DSCT) systems. ${ }^{7-12}$ Due to technological advancements, the diagnostic quality of MDCT coronary angiography has improved substantially. Several studies have shown an excellent correlation with invasive coronary angiography for the diagnosis of significant CAD. ${ }^{13-15}$ Recent studies suggested the superior cost-effectiveness of MDCT coronary angiography in diagnosing CAD. However, those studies were mainly computer simulations of idealised model situations. Importantly, only basic 64-row MDCT systems were studied and some results were constrained by methodological inaccuracies, such as applying inconsistent cost-accounting practices. ${ }^{16-19}$ Thus, the true cost position of latest-generation MDCT scanners in evaluating patients with suspected CAD remains somewhat unclear.

The current study therefore aimed to determine the direct costs and cost-effectiveness of DSCT coronary angiography as an alternative to invasive coronary angiography in a patient cohort with an intermediate likelihood of $\mathrm{CAD}$.

\section{MATERIALS AND METHODS \\ Patients}

We analysed the direct costs for diagnostic coronary imaging at a single centre. The study included a total of 90 consecutive patients without a history of $\mathrm{CAD}$ who were referred for invasive coronary angiography. Inclusion criteria and clinical details of the patients have been described in a previous article. ${ }^{20}$ Briefly, the patients (mean age $58 \pm 8$ years, $63 \%$ male) had uninterpretable or equivocal noninvasive stress tests and an intermediate pretest likelihood for significant $\mathrm{CAD}$ according to the score of Morise et al (9-15 points). ${ }^{21}$ Presenting symptoms included typical angina $(n=20)$, atypical angina $(n=53)$ and dyspnoea $(n=17)$. Patients with a positive stress test and/or a high ( $>15$ points) or low ( $<9$ points) pretest likelihood were excluded 
from the study. All patients underwent DSCT the day before they underwent invasive coronary angiography. The study protocol was approved by the institutional review board, and written informed consent was obtained from all patients.

\section{DSCT coronary angiography}

Full details of the scanning protocol have been published previously, and only a brief summary is described here. ${ }^{20}{ }^{22}$ CT coronary angiography was performed using a DSCT scanner (Somatom Definition, Siemens Healthcare, Forchheim, Germany), which uses two x-ray sources and two detectors simultaneously. The parameters for the acquisition were a gantry rotation time of $0.33 \mathrm{~s}$, a tube voltage of $120 \mathrm{kV}$ for both tubes, a tube current of $560 \mathrm{mAs}$ (using modulation), a slice collimation of $64 \times 0.6 \mathrm{~mm}$ and a pitch of $0.2-0.44$ adapted to heart rate. Prior to the scan, no negative chronotropic premedication was given. A body-weight-adapted $\left(1.25 \mathrm{~cm}^{3} / \mathrm{kg}\right.$ body weight) volume of the contrast agent iopromide (Ultravist ${ }^{\circledR} 370$, Schering, Berlin, Germany) was injected continuously during a period of $20 \mathrm{~s}$ followed by a saline flush $\left(100 \mathrm{~cm}^{3}\right.$ at $\left.5 \mathrm{~cm}^{3} / \mathrm{s}\right)$. Axial images were reconstructed at a slice thickness of $0.75 \mathrm{~mm}$ and an increment of $0.5 \mathrm{~mm}$ using a B26 kernel and retrospective ECG gating. The DSCT data sets were read by an experienced physician immediately after the exam using a dedicated cardiac workstation (Leonardo, Siemens Healthcare). Each coronary segment was judged as non-stenosed (no stenosis, $<50 \%$ ), intermediately diseased ( $>50 \%$ to $<75 \%$ diameter stenosis) or significantly diseased ( $>75 \%$ diameter stenosis) using a modified American Heart Association segment model. ${ }^{23}$

\section{Invasive coronary angiography}

An independent external cardiologist determined the indication for invasive coronary angiography. In all patients, conventional coronary angiography was performed using standard techniques 1 day after DSCT coronary angiography. Vascular access was obtained through a femoral approach using the Seldinger technique with $6 \mathrm{~F}$ or $7 \mathrm{~F}$ catheters. At least three standard projections including a $45^{\circ}$ left anterior oblique, a $30^{\circ}$ right anterior oblique and a $45^{\circ}$ left anterior and $30^{\circ}$ cranial projection were acquired for both coronary arteries with a single-plane, floor-mounted angiography system (Coroskop HIP, Siemens Healthcare). For coronary angiography, iomeprol (Imeron ${ }^{\circledR}$ 350, Bracco Altana, Konstanz, Germany) was administered. Invasive coronary angiography served as the reference standard for the determination of CAD. Thus, all coronary angiograms were evaluated by quantitative coronary angiography (QuantCor, Siemens Healthcare). For coronary artery lesions, the mean diameter reduction was determined in two projections. The DSCT diagnostic criteria for intermediate and significant $\mathrm{CAD}$ also applied to invasive coronary angiography.

\section{Cost analysis}

In the economical evaluation, the costs (in euros) of both diagnostic approaches were identified through a detailed analysis of all involved procedures. Direct costs were composed of three categories: diagnostic-specific equipment costs, materials and supplies costs and personnel costs. Equipment costs included purchasing, maintenance and repair (excluding major improvements and system upgrades) as well as financing costs (average annual interest payments). Installation contracts provided for a defects liability period. On-site clinical training was also included as part of the contract. Cost of materials and supplies reflected market prices paid to manufacturers and vendors. Occupancy costs included heating, air-conditioning, light, cleaning, insurance, security and others. Personnel costs were salaries and wages including social security, pension and other related contributions. Other analyses (eg, ECG, blood tests and physical examination) carried out before the actual procedures were not taken into account and were considered identical for both diagnostic strategies. Hospitalisation costs before and after the procedure, except for the 6-h observation period following diagnostic catheterisation, were also not taken into account because they were dependent on comorbidities and other patient-independent factors. ${ }^{24}$ Contributions to overhead were not included.

In the cost analysis, the following general assumptions were taken into account: equipment lifetime for all systems was set at 8 years. Operational hours for both the DSCT scanner and the cardiac catheterisation laboratory were $8 \mathrm{~h} /$ day, 254 days/year. All involved physicians, nurses and technicians were salaried hospital employees. Thus, personnel costs were calculated according to collective agreements for German public service employees including additional provisions for vacation, sick leave and continuing education (25\% on average). Where applicable, costs included value-added tax at $19 \%$.

\section{Cost-effectiveness analysis}

A cost-effectiveness analysis was conducted from the provider perspective. The key effectiveness criterion was the ability of a diagnostic test to identify accurately a patient who has CAD based on morphological criteria describing coronary artery luminal integrity. ${ }^{25-27}$ This straightforward approach assumes that the goal of a test is to make a diagnosis. ${ }^{27}$ Cost-effectiveness was defined as cost per effect. ${ }^{26} 27$

\section{$\underline{\text { Direct Costs }+ \text { Induced Costs }}$ \\ Effectiveness}

Total costs were calculated as direct costs (as established by the cost analysis) times the number of patients tested plus the induced costs (the number of patients tested multiplied by the costs of complications produced by test procedures or of CAD missed by false-negative test results).$^{25-27}$ By definition, invasive coronary angiography was the gold-standard test in the costeffectiveness analysis with a 100\% diagnostic accuracy (sensitivity $\left(\mathrm{Sn}_{\mathrm{A}}\right)$ and specificity $\left(\mathrm{Sp}_{\mathrm{A}}\right)$ of invasive coronary angiography $=100 \%$ ) and no non-diagnostic results. The mathematical model to compare cost-effectiveness of DSCT coronary angiography and invasive angiography is a modification of the equations of Bayes' theorem and has been previously described. ${ }^{26} 27$ Specifically, the model involves the equations below (box 1 shows parameters used in equations). In the first algorithm, DSCT coronary angiography would be performed first followed by invasive angiography but only if DSCT coronary angiography is positive or non-diagnostic (figure 1A).

1. DSCT coronary angiography
a. Costs $=\mathrm{N}_{\mathrm{CT}} \times\left(\mathrm{D}_{\mathrm{CT}}+\mathrm{R}_{\mathrm{CT}} \times \mathrm{C}\right)+\mathrm{N}_{\mathrm{A}} \times\left(\mathrm{D}_{\mathrm{A}}+\mathrm{R}_{\mathrm{A}} \times \mathrm{C}\right)$ $+\mathrm{N}_{\mathrm{F}} \times\left(\mathrm{R}_{\mathrm{F}} \times \mathrm{C}\right)$ whereas $\mathrm{N}_{\mathrm{A}}=\mathrm{N}_{\mathrm{CT}} \times\left(1-\mathrm{NDx}_{\mathrm{CT}}\right) \times\left[\mathrm{P} \times \mathrm{Sn}_{\mathrm{CT}}+(1-\mathrm{P}) \times\left(1-\mathrm{Sp}_{\mathrm{CT}}\right)\right]$ $+\mathrm{N}_{\mathrm{CT}} \times \mathrm{NDx}_{\mathrm{CT}}$ and $\mathrm{N}_{\mathrm{F}}=\mathrm{N}_{\mathrm{CT}} \times\left(1-\mathrm{NDx}_{\mathrm{CT}}\right) \times \mathrm{P} \times\left(1-\mathrm{Sn}_{\mathrm{CT}}\right)$
b. Effectiveness $=\mathrm{N}_{\mathrm{CT}} \times\left(1-\mathrm{NDx}_{\mathrm{CT}}\right) \times$ $\mathrm{P} \times \mathrm{Sn}_{\mathrm{CT}}+\mathrm{N}_{\mathrm{CT}} \times \mathrm{P} \times \mathrm{NDx} \mathrm{x}_{\mathrm{CT}}$

In the alternative diagnostic algorithm, invasive coronary angiography would be the first and only test to diagnose CAD (figure 1B).

2. Invasive coronary angiography

c. Costs $=\mathrm{N}_{\mathrm{A}} \times\left(\mathrm{D}_{\mathrm{A}}+\mathrm{R}_{\mathrm{A}} \times \mathrm{C}\right)$ whereas $\mathrm{N}_{\mathrm{A}}=1.0$

d. Effectiveness $=\mathrm{N}_{\mathrm{A}} \times \mathrm{P}$ 


\section{Box 1 Parameters used in calculations}

- $\mathrm{D}_{\mathrm{CT}}$, direct costs for DSCT coronary angiography

- $D_{A}$, direct costs for invasive coronary angiography

- C, average costs of a complication (assumed to be non-fatal myocardial infarction or stroke)

- $\mathrm{R}_{\mathrm{CT}}$, rate of complications with DSCT coronary angiography

- $\mathrm{R}_{\mathrm{A}}$, rate of complications with invasive coronary angiography

- $\mathrm{R}_{\mathrm{F}}$, rate of complications per 10-year follow-up period for patients with CAD and false-negative tests

- $\mathrm{Sn}_{\mathrm{CT}}$, sensitivity of DSCT coronary angiography

- $\mathrm{Sp}_{\mathrm{CT}}$, specificity of DSCT coronary angiography

- $\mathrm{Sn}_{\mathrm{A}}$, sensitivity of invasive coronary angiography

- $\mathrm{Sp}_{\mathrm{A}}$, specificity of invasive coronary angiography

- $\mathrm{NDx}_{\mathrm{CT}}$, rate of non-diagnostic DSCT coronary angiography

- $\mathrm{N}_{\mathrm{CT}}$, number of patients having DSCT coronary angiography

- $\mathrm{N}_{\mathrm{A}}$, number of patients having invasive coronary angiography

- $\mathrm{N}_{\mathrm{F}}$, number of patients with false-negative DSCT coronary angiography who do not have invasive coronary angiography

- $P$, prevalence of CAD in patient cohort

CAD, coronary artery disease; DSCT, dual-source computed tomography.

Costs of complications (C) are difficult to estimate. ${ }^{162627}$ For this purpose, previously published data were combined. It was assumed that the typical complication of both diagnostic tests or of untreated CAD would be non-fatal myocardial infarction (or cerebrovascular, for invasive angiography), requiring hospitalisation, rehabilitation, chronic medication and repeated follow-up examinations. On average, conservative cost estimates for a serious complication amounted to $€ 14478 .{ }^{16}{ }^{17} \quad 28-30$ Complication rates for MDCT $\left(\mathrm{R}_{\mathrm{CT}}=0.004 \%\right)$ and elective invasive coronary angiography $\left(\mathrm{R}_{\mathrm{A}}=0.05 \%\right)$ were derived from the literature. ${ }^{16} 24{ }^{31}$ The potential risk of radiation-induced malignancies from a single DSCT or angiography exposure is difficult to assess and was therefore not incorporated in the model assumptions. For the same reason, the costs of follow-up of incidental non-cardiac findings on DSCT were not included. ${ }^{32}$ In the subgroup of patients with false-negative DSCT coronary angiography, a $15 \%$ rate $\left(\mathrm{R}_{\mathrm{F}}\right)$ of non-fatal myocardial infarction

A

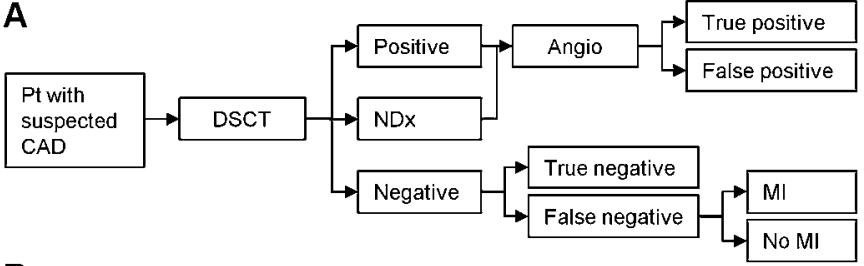

B

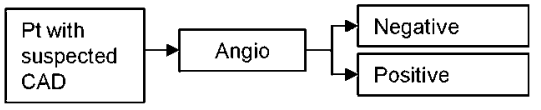

Figure 1 Decision tree model for patients (Pt) presenting with suspected coronary artery disease (CAD). Strategy A involved dualsource computed tomography (DSCT) coronary angiography. Patients with positive or non-diagnostic (NDx) DSCT underwent invasive coronary angiography (Angio), which either confirmed or refuted the DSCT diagnosis. Patients with false-negative DSCT findings were at risk for myocardial infarction (MI) from undetected CAD. In strategy $B$, invasive coronary angiography was the first and only test to diagnose CAD. over 10 years was assumed. ${ }^{27}$ Costs associated with a falsenegative test did not include costs for malpractice settlement or costs of a trial. Future complication-related costs were discounted annually at a rate of $3 \%$. Cost-effectiveness calculations were carried out over the full range of $\mathrm{CAD}$ prevalence $(\mathrm{P})$ $(\mathrm{P}=10-100 \%)$ under special consideration of our intermediate risk cohort.

\section{Sensitivity analysis}

A sensitivity analysis was performed to evaluate whether some key parameters used in the mathematical model are robust within a certain range of uncertainty. Thus, cost-effectiveness calculations were repeated after (1) increasing and decreasing the rates of complications associated with invasive coronary angiography $\left(\mathrm{R}_{\mathrm{A}}=0.1 \%\right.$ and $\left.0.01 \%\right)$, (2) taking into account higher and lower costs of complications ( $\mathrm{C}=€ 25000$ and $€ 10000)$, (3) increasing and decreasing DSCT coronary angiography sensitivity $\left(\mathrm{Sn}_{\mathrm{CT}}=98 \%\right.$ and $\left.92 \%\right)$ and specificity $\left(\mathrm{Sp}_{\mathrm{CT}}=93 \%\right.$ and $87 \%)$, (4) assuming higher and lower rates of complications resulting from false-negative DSCT coronary angiography $\left(\mathrm{R}_{\mathrm{F}}=30 \%\right.$ and $\left.10 \%\right)$ and (5) increasing and decreasing the discount rate $(5 \%$ and $0 \%)$.

\section{Statistical analysis}

Confidence intervals were determined for sensitivity, for specificity and for negative and positive predictive values on a per-patient basis. The statistical analysis was made using the MedCalc program (MedCalc, Mariakerke, Belgium).

\section{RESULTS}

\section{Diagnostic accuracy to detect CAD}

Dual-source CT image quality was graded sufficient for analysis in 88 of 90 (98\%) patients. Two patients with insufficient image quality because of motion artefacts were excluded from the accuracy analysis (rate of non-diagnostic DSCT coronary angiography $\left.\left(\mathrm{NDx}_{\mathrm{CT}}\right)=2 \%\right)$. On a per-patient basis and as diagnosed as having invasive coronary angiography, 9 patients had at least one coronary artery stenosis $>75 \%$ and 12 patients had at least one stenosis that was $50 \%$ to $75 \%$ of luminal diameter. Hence, the prevalence of CAD (P) was $24 \%$. All patients with a stenosis $>75 \%$ and 11 of 12 patients with a stenosis ranging from $50 \%$ to $75 \%$ were correctly identified by DSCT. In seven patients without significant CAD (stenosis $>50 \%$ ), three patients were incorrectly diagnosed by DSCT to have at least one stenosis $>75 \%$ and four patients were incorrectly diagnosed to have at least one stenosis of between $50 \%$ and $75 \%$. The data expressing patient-based diagnostic accuracy are given in table 1 . Importantly, overall sensitivity $\left(\mathrm{Sn}_{\mathrm{CT}}\right)$ and specificity $\left(\mathrm{Sp}_{\mathrm{CT}}\right.$ ) of DSCT coronary angiography were $95 \%$ and $90 \%$, respectively. Results of DSCT coronary angiography were false-negative in one patient $\left(N_{F}=1 \%\right)$. Further details of this

Table 1 Patient-based diagnostic accuracy of DSCT to detect coronary artery stenoses

\begin{tabular}{cllll}
\hline $\begin{array}{c}\text { Degree of } \\
\text { stenoses }\end{array}$ & Sensitivity & Specificity & PPV & NPV \\
\hline $50-75 \%$ & $11 / 12(92 \%)$ & $63 / 67(94 \%)$ & $11 / 15(73 \%)$ & $59 / 60(99 \%)$ \\
$95 \% \mathrm{Cl}$ & $62 \%$ to $99 \%$ & $85 \%$ to $98 \%$ & $44 \%$ to $92 \%$ & $91 \%$ to $100 \%$ \\
$>75 \%$ & $9 / 9(100 \%)$ & $76 / 79(96 \%)$ & $9 / 12(75 \%)$ & $76 / 76(99 \%)$ \\
$95 \% \mathrm{Cl}$ & $66 \%$ to $99 \%$ & $89 \%$ to $99 \%$ & $42 \%$ to $94 \%$ & $95 \%$ to $100 \%$ \\
$\mathrm{All}>50 \%$ & $20 / 21(95 \%)$ & $60 / 67(90 \%)$ & $20 / 27(74 \%)$ & $60 / 61(99 \%)$ \\
$95 \% \mathrm{Cl}$ & $76 \%$ to $99 \%$ & $80 \%$ to $95 \%$ & $58 \%$ to $89 \%$ & $91 \%$ to $99 \%$ \\
\hline
\end{tabular}

DSCT, dual-source computed tomography; NPV, negative predictive value; PPV, positive predictive value. 
cohort have been reported previously. ${ }^{20}$ No actual complications related to DSCT or invasive coronary angiography were observed. However, for calculation purposes, the above-described rates of complications were used.

\section{Cost analysis}

DSCT coronary angiography

Findings on direct costs for DSCT coronary angiography are presented in table 2 . Unit costs represent either purchasing costs, annual average costs or costs for a given quantity of material (quantities in brackets). The calculated costs per examination are shown in the right column. The calculations were based on the above-mentioned general assumptions for cost analysis and, in addition, on specific time requirements for DSCT coronary angiography. These included 15 min of total DSCT scanner room time and $30 \mathrm{~min}$ for postprocessing, reporting and archiving on a separate workstation. Cardiologists and radiographers were allotted 20 and 25 min per examination, respectively. Purchasing costs involved installation costs as well as all associated building renovations necessary to accommodate the DSCT scanner. The manufacturer's full service contract included x-ray tubes and preventive maintenance. Surface area for installation was $40 \mathrm{~m}^{2}$, providing sufficient floor space for the DSCT scanner room as well as for the control room. On average, $107 \mathrm{~cm}^{3}$ of contrast agent and $100 \mathrm{~cm}^{3}$ of saline were used per patient. The total direct cost of a DSCT coronary angiography ( $\mathrm{D}_{\mathrm{CT}}$ ) study amounted to $€ 98.60$.

\section{Invasive coronary angiography}

Table 3 lists the costs associated with invasive coronary angiography. Calculated effective costs per examination are depicted in the right column. Overall cardiac catheterisation laboratory utilisation time for a diagnostic coronary angiography was $30 \mathrm{~min}$. A cardiologist was present for $30 \mathrm{~min}$, a radiographer was present for $35 \mathrm{~min}$ and a nurse was present for $50 \mathrm{~min}$ (the latter time included an average of $15 \mathrm{~min}$ for patient care during the $6-h$ postcatheterisation observation period). In general,

Table 2 DSCT coronary angiography cost breakdown

\begin{tabular}{|c|c|c|}
\hline Cost category & $\begin{array}{l}\text { Unit costs } \\
\text { (in } €)\end{array}$ & $\begin{array}{l}\text { Costs per } \\
\text { examination } \\
(\text { in } €)\end{array}$ \\
\hline \multicolumn{3}{|l|}{ Equipment costs } \\
\hline Siemens Somatom Definition & 1612000.00 & 24.79 \\
\hline Separate CT workstation & 68310.00 & 2.10 \\
\hline DSCT full service contract (per year) & 114850.00 & 14.13 \\
\hline Dual-head injector & 42513.00 & 0.65 \\
\hline Injector service contract (per year) & 2200.00 & 0.27 \\
\hline Electricity, water and IT connectivity (per year) & 10575.50 & 1.73 \\
\hline Occupancy costs $\left(40 \mathrm{~m}^{2}\right)$ (per year) & 7508.40 & 1.23 \\
\hline Financing costs (interest rate $5.0 \%$ ) (per year) & 44627.00 & 5.49 \\
\hline \multicolumn{3}{|l|}{ Materials and supplies costs } \\
\hline Contrast agent (Ultravist $\left.{ }^{\circledR} 370\right)\left(100 \mathrm{~cm}^{3}\right)$ & 6.50 & 6.95 \\
\hline Saline $\left(500 \mathrm{~cm}^{3}\right)$ & 0.73 & 0.15 \\
\hline $\begin{array}{l}\text { Intravenous cannula (18G) (including } \\
\text { disinfectant and dressing) }\end{array}$ & 0.62 & 0.62 \\
\hline Dual syringe kit with tubing and connector & 9.09 & 9.09 \\
\hline Disposable ECG electrode & 0.23 & 0.90 \\
\hline Archiving (PACS) & 1.35 & 1.35 \\
\hline \multicolumn{3}{|l|}{ Personnel costs } \\
\hline Physician (per year) & 107359.20 & 18.64 \\
\hline Radiographer (per year) & 49920.00 & 10.50 \\
\hline Total & & 98.60 \\
\hline
\end{tabular}

preparation and documentation of a case were included in the times allotted. The main components of the cardiac catheterisation laboratory infrastructure were the single-plane angiography system and the haemodynamic recording system. Equipment costs included all costs of installation and implementation. The full service contract covered all travel and personnel costs for unscheduled breakdown visits as well as major replacement items such as image intensifiers and x-ray tubes. The size of the cardiac catheterisation laboratory was $85 \mathrm{~m}^{2}$, allowing for adequate space for procedure, control, technical and storage rooms. Adjacent to the catheterisation laboratory, there was an eight-bed holding area (approximately $9 \mathrm{~m}^{2}$ floor space per bed) with telemetry monitoring. As far as materials and supplies are concerned, a multiplication factor of two had to be applied for compact disks and a factor of four for $10-\mathrm{cm}^{3}$ syringes, sterile compresses (10 packs) and disposable ECG electrodes. A mean of $80 \mathrm{ml}$ of contrast agent was used per patient. Direct invasive coronary angiography costs $\left(D_{A}\right)$ totalled $€ 317.75$

Cost comparison-DSCT versus invasive coronary angiography

Summarised cost categories are displayed in table 4. Equipment costs were nearly the same for both diagnostic approaches. However, materials and supplies costs of invasive coronary

Table 3 Invasive coronary angiography cost breakdown

\begin{tabular}{|c|c|c|}
\hline Cost category & $\begin{array}{l}\text { Unit costs } \\
\text { (in €) }\end{array}$ & $\begin{array}{l}\text { Costs per } \\
\text { examination } \\
(\text { in } €)\end{array}$ \\
\hline \multicolumn{3}{|l|}{ Equipment costs } \\
\hline Siemens Coroskop HIP & 849219.00 & 26.12 \\
\hline $\begin{array}{l}\text { Haemodynamic recording system } \\
\text { (Axiom Sensis) }\end{array}$ & 82300.00 & 2.53 \\
\hline Full service contract (per year) & 41445.00 & 10.20 \\
\hline $\begin{array}{l}\text { Electricity, water and IT connectivity } \\
\text { (per year) }\end{array}$ & 8433.00 & 2.08 \\
\hline Occupancy costs $\left(85 \mathrm{~m}^{2}\right)$ (per year) & 22525.20 & 3.93 \\
\hline Holding area ( $9 \mathrm{~m}^{2} /$ bed) (per year) & 1689.39 & 4.99 \\
\hline $\begin{array}{l}\text { Financing costs (interest rate } 5.0 \% \text { ) } \\
\text { (per year) }\end{array}$ & 25075.00 & 6.17 \\
\hline \multicolumn{3}{|l|}{ Materials and supplies costs } \\
\hline Set of sterile gloves, gowns and drapes & 53.31 & 53.31 \\
\hline Arterial puncture needle (18G) & 2.11 & 2.11 \\
\hline Syringe $10 \mathrm{~cm}^{3}$ & 0.12 & 0.48 \\
\hline $\begin{array}{l}\text { Standard catheter set (including JL, JR, } \\
\text { sheaths, guidewires and pigtail catheter) }\end{array}$ & 50.39 & 50.39 \\
\hline Contrast agent (Imeron $\left.{ }^{\circledR} 350\right)\left(100 \mathrm{~cm}^{3}\right)$ & 7.22 & 5.78 \\
\hline Arterial blood sampling syringe & 0.77 & 0.77 \\
\hline Local anaesthetics (Xylonest $\left.{ }^{\circledR} 2 \%\right)\left(20 \mathrm{~cm}^{3}\right)$ & 2.17 & 2.17 \\
\hline Heparin (5000 IU) & 0.12 & 0.12 \\
\hline Glyceryl trinitrate $\left(1 \mathrm{~cm}^{3}\right)$ & 0.07 & 0.07 \\
\hline Disposable infusion system & 0.29 & 0.29 \\
\hline Disposable ECG electrode & 0.23 & 0.90 \\
\hline Sterile compresses (10 packs) & 0.05 & 0.20 \\
\hline Saline $\left(500 \mathrm{~cm}^{3}\right)$ & 0.73 & 0.73 \\
\hline Sterile drapes for angiography system & 2.30 & 2.30 \\
\hline $\begin{array}{l}\text { Intravenous cannula (18G) (including } \\
\text { disinfectant and dressing) }\end{array}$ & 0.62 & 0.62 \\
\hline Vascular closure device (Angioseal ${ }^{\circledR}$ ) & 77.35 & 77.35 \\
\hline Archiving (CD) & 0.39 & 0.78 \\
\hline \multicolumn{3}{|l|}{ Personnel costs } \\
\hline Cardiologist (per year) & 107359.20 & 27.96 \\
\hline Cardiac cath lab radiographer (per year) & 49920.00 & 14.58 \\
\hline Cardiac cath lab nurse (per year) & 49920.00 & 20.83 \\
\hline Total & & 317.75 \\
\hline
\end{tabular}


angiography were approximately 10-fold, and personnel costs were nearly double when compared to DSCT coronary angiography.

\section{Cost per patient tested and cost-effectiveness}

Figure 2 shows the cost per patient tested in relation to different prevalences of CAD. These results indicate that the direct costs only represented one component of total costs incurred by a diagnostic test. The cost for DSCT coronary angiography increased as a linear function of CAD prevalence. In contrast, the cost for invasive coronary angiography did not increase significantly. Figure 3 plots cost per effect (cost per patient with CAD diagnosed accurately) versus increasing prevalences of CAD. As cost per effect is the inverse of cost-effectiveness, the hyperbolic decrease in cost per effect indicates increased cost-effectiveness. Despite the increase in total cost with increasing prevalence of $\mathrm{CAD}$, cost-effectiveness improved with higher $\mathrm{CAD}$ prevalence for both diagnostic tests. In comparison, DSCT coronary angiography was more cost-effective up to a CAD prevalence of $48 \%$. Given the $24 \%$ CAD prevalence of the investigated patient cohort, cost for one patient correctly diagnosed as having CAD was $€ 970$ with DSCT and $€ 1354$ with invasive angiography (figure 3). At a CAD prevalence of $49 \%$, DSCT and invasive angiography were equally effective with costs of $€ 633$. With higher disease prevalences, invasive coronary angiography became more cost-effective.

\section{Sensitivity analysis}

In order to evaluate the robustness of the mathematical model and to address uncertainty, we systematically changed the numerical values of some key parameters in the equations. Increasing $(0.1 \%)$ or decreasing $(0.01 \%)$ the rates of complications associated with invasive coronary angiography changed the cost-effectiveness threshold of DSCT significantly $(52 \%$ and $47 \%$ CAD prevalence, respectively). With higher (€25000) and lower (€10000) costs of complications, DSCT remained costeffective up to a CAD prevalence of $42 \%$ and $52 \%$, respectively. The most substantial changes occurred at maximally decreased and increased diagnostic accuracies. However, DSCT coronary angiography remained more cost-effective than invasive angiography up to a disease prevalence of $41 \%$ and $55 \%$, respectively. After elevating (30\%) and lowering (10\%) the risk of non-fatal myocardial infarction because of false-negative test results, DSCT coronary angiography remained comparably more costeffective up to a CAD prevalence of $40 \%$ and $53 \%$, respectively. Using discount rates for future complication-related costs of $0 \%$ and $5 \%$ (base case $3 \%$ ), we found that DSCT was still costeffective up to a CAD prevalence of $46 \%$ and $51 \%$, respectively. Thus, sensitivity analysis revealed cost-effectiveness of wellperformed DSCT coronary angiography in diagnosing CAD up to an average disease prevalence of $40 \%$. When disease prevalence was higher than $55 \%$, direct invasive coronary angiography was more cost-effective.

Table 4 Cost comparison-DSCT versus invasive coronary angiography

\begin{tabular}{llc}
\hline Cost category & $\begin{array}{l}\text { DSCT coronary } \\
\text { angiography (in } € \text { ) }\end{array}$ & $\begin{array}{l}\text { Invasive coronary } \\
\text { angiography (in } € \text { ) }\end{array}$ \\
\hline Equipment & 50.40 & 56.01 \\
Materials and supplies & 19.06 & 198.37 \\
Personnel & 29.14 & 63.37 \\
Total & 98.60 & 317.75 \\
\hline
\end{tabular}

DSCT, dual-source computed tomography.

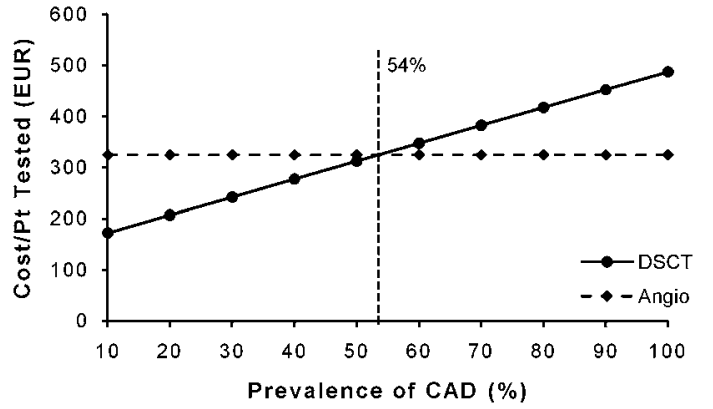

Figure 2 The graph shows the cost per patient (Pt) tested on the vertical axis for dual-source computed tomography (DSCT) and invasive coronary angiography (Angio). Prevalence of coronary artery disease (CAD) increases along the horizontal axis. Cost increases with CAD prevalence for DSCT coronary angiography but not significantly for invasive coronary angiography. DSCT showed lower cost than invasive angiography with $C A D$ prevalence $<54 \%$ but higher costs with $C A D$ prevalence $\geq 54 \%$.

\section{DISCUSSION \\ Main findings}

To the best of our knowledge, this is the first study to evaluate the cost-effectiveness of a latest-generation DSCT scanner in diagnosing $\mathrm{CAD}$ in a well-defined cohort of patients with an intermediate pretest disease likelihood. For the first time, generally accepted business accounting principles were applied and the cost calculations were based on a detailed analysis of direct costs. Compared to the gold standard of invasive coronary angiography, DSCT coronary angiography was found to be cost-effective up to an average disease prevalence of $40 \%$. Above a threshold value of disease prevalence of $55 \%$, proceeding directly to invasive coronary angiography was more cost-effective than DSCT.

\section{Assessment of cost-effectiveness}

In the past years, there has been an increasing awareness of the need to consider cost in medical decision-making. ${ }^{33}$ Cost-effectiveness analysis can help medical decision-makers to target scarce healthcare resources more efficiently and can guide utilisation of latest-generation and often high-cost diagnostic imaging modalities. ${ }^{34} 35$

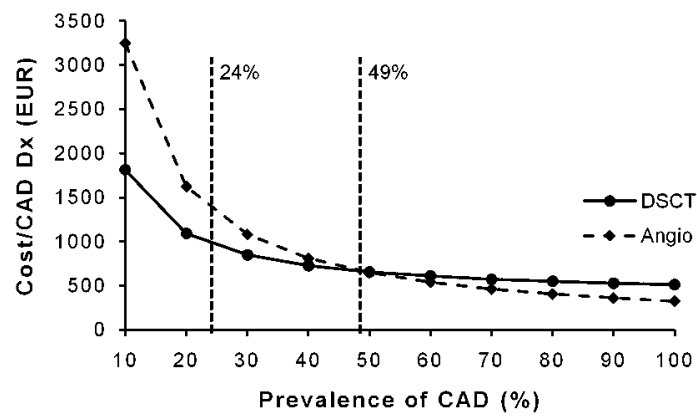

Figure 3 The graph shows cost per effect (cost per patient with coronary artery disease (CAD) diagnosed (Dx) correctly) on the vertical axis. As the prevalence of CAD increases along the horizontal axis, the cost per effect (or cost-effectiveness-1) decreases. At low CAD prevalence, cost per effect is lower for dual-source computed tomography (DSCT) than for invasive coronary angiography (Angio). Invasive angiography shows lower cost per effect than DSCT with CAD prevalence $>49 \%$. The CAD prevalence of the investigated patient cohort was $24 \%$ (also shown in the graph). 
A major challenge in cost-effectiveness analysis is the identification of all relevant costs. Importantly, costs should be defined in an unambiguous way and should not be confused with charges or reimbursement fees. ${ }^{33}$ Direct costs reflect the value of resources that are actually paid for. ${ }^{33} 36$ The overall direct costs of invasive coronary angiography were found to be about three times the cost of DSCT coronary angiography, mainly due to higher materials and supplies costs and personnel costs. This ratio is markedly lower than those reported in previous studies, which have found that the cost of invasive coronary angiography exceeds that of 64-row MDCT coronary angiography up to a factor of nine. ${ }^{1617} 19$ However, the latter studies have, at least partly, applied inconsistent cost-accounting practices, and thus, the results might not be directly comparable. In particular, reimbursement fees were misleadingly mixed with or were taken as a surrogate for direct costs, resulting in disproportionately high costs of invasive coronary angiography. Although the price of a DSCT scanner significantly exceeds that of a 64-row MDCT scanner, the comparably low cost ratio between DSCT and invasive coronary angiography found in our data cannot be attributed to higher DSCT purchasing costs. In fact, total direct costs of DSCT were even lower than those of 64-row MDCT, mainly due to a relative reduction in personnel costs. ${ }^{17}$ This cost reduction may be, at least partly, achieved by DSCT features such as imaging without $\beta$ blockers, which minimises prescan preparation, in-room time and the postscan observation period. However, the main factor that contributes to the low cost ratio between DSCT and invasive coronary angiography is the relatively low direct costs of invasive coronary angiography, reflecting an increasingly professional cardiac catheterisation laboratory management and various cost containment strategies. ${ }^{37}$ As this study assumes a healthcare provider's perspective and not a societal one, indirect costs such as lost productivity due to missed work were excluded. ${ }^{33}$ It was not our goal to assess the impact of diagnostic tests of $\mathrm{CAD}$ on the welfare of society. ${ }^{26}$ This more complex task would have required a costbenefit analysis. ${ }^{33} 38$ Rather, the objective of the study is to compare the costs of two diagnostic approaches to achieve the same effect, that is, diagnosing CAD.

The diagnostic accuracy of DSCT to detect coronary artery stenoses (table 1) was similar to that reported in other DSCT studies. ${ }^{39} 40$ In patient populations comparable to those of our current study, the clinical usefulness of 64-row MDCT coronary angiography has recently been corroborated. ${ }^{41}{ }^{42}$ Compared to single-source 64-row MDCT, DSCT coronary angiography shows better image quality and provides comparable or slightly improved diagnostic accuracy. ${ }^{43} 44$ It has been shown that the pretest likelihood of CAD may impact the diagnostic accuracy of MDCT coronary angiography. ${ }^{45}$ Thus, pooled diagnostic accuracies, stemming mainly from cohorts with high pretest likelihoods $(>80 \%)$, cannot be extrapolated to cohorts with low $(<20 \%)$ or intermediate $(20-80 \%)$ pretest likelihoods. ${ }^{16} 1745$ According to recent recommendations, MDCT coronary angiography should only be carried out on selected patients, principally those who have an intermediate pretest likelihood of CAD or who have uninterpretable or equivocal stress tests. ${ }^{46}$ MDCT is of limited clinical value in patients with a high pretest likelihood of $\mathrm{CAD}$ because the majority of patients with symptoms are likely to proceed straight to invasive coronary angiography and particularly because angiography and percutaneous coronary interventions are often done on the same occasion. ${ }^{45-47}$ In patients with a low pretest likelihood of $\mathrm{CAD}$, stress testing is recommended because of low cost, safety and absence of ionising radiation. ${ }^{46} 47$
Although the cost per patient tested increased linearly along with an increase in disease prevalence (figure 2), cost-effectiveness (cost per effect) analysis showed a hyperbolic decrease in costs (figure 3 ). This observation is due to the fact that the employed mathematical model defines a patient correctly diagnosed as having $\mathrm{CAD}$ as the effect in the cost-effectiveness analysis and that this effect becomes more frequent with an increase in disease prevalence. ${ }^{162627}$ Specifically, the effect was based on morphological criteria of coronary artery luminal anatomy and integrity. ${ }^{48}$ Physiological testing, including assessment of the functional significance of a coronary artery stenosis or examining myocardial viability, was not addressed by our study. Although both anatomical and physiological tests are important in the management of patients suspected of having CAD, they provide fundamentally different information and their results might therefore not be directly comparable. ${ }^{16} \mathrm{At}$ low CAD prevalences, DSCT coronary angiography was more cost-effective than invasive angiography (figure 3). It is perfectly reasonable that negative DSCT results will reduce the number of invasive coronary angiographies at low disease prevalences $(<40 \%)$ because nearly all DSCT tests will be correct to rule out $\mathrm{CAD}$ (high negative predictive value of DSCT coronary angiography at lower prevalences of CAD) (table 1). ${ }^{45} 4748$ In contrast, at higher disease prevalences, DSCT starts to miss patients who actually have $\mathrm{CAD}$ and the costs of complications resulting from false-negative DSCT examinations decrease cost-effectiveness. Above a threshold value of $>55 \%$ disease prevalence, performing invasive coronary angiography as the first and only test was more cost-effective. A previous study demonstrated that 64-row MDCT coronary angiography is cost-effective in patients with a $10-50 \%$ pretest likelihood for $\mathrm{CAD}$, whereas invasive coronary angiography is the most cost-effective preferred approach in patients with a likelihood for disease $>60 \% .{ }^{16}$ Another study found 64-row MDCT to be more cost-effective than invasive coronary angiography even up to a pretest likelihood for CAD of $86 \% .{ }^{17}$ However, these studies applied different cost-accounting practices and largely overestimated the costs of invasive coronary angiography or the rate of severe complications associated with elective cardiac catheterisation. ${ }^{16} 17$ Based on our own calculations and in comparison with the available studies, we found the threshold value for cost-effectiveness of DSCT coronary angiography somewhat lower (up to $40 \%$ disease prevalence). From a cost-effective point of view, our results indicate that the range of patients eligible for CT coronary angiography is smaller than previously believed and that invasive coronary angiography becomes the more cost-effective diagnostic approach at a disease prevalence $>55 \%$. These findings are supported by recent guidelines on the assessment and diagnosis of recent onset chest pain issued by the National Institute for Health and Clinical Excellence. ${ }^{49}$ According to National Institute for Health and Clinical Excellence guidelines, CT coronary angiography is recommended if a patient has a $10-29 \%$ pretest likelihood for $\mathrm{CAD}$. The guideline further recommends invasive coronary angiography as the most cost-effective first test if the likelihood of CAD is $>61 \%$. ${ }^{49}$

Our study has potential limitations. First, patients were not randomised as to the order of imaging studies. However, DSCT and invasive coronary angiography were interpreted by readers who were blinded to the results of the other imaging study, and thus, it is unlikely that any bias was introduced. Second, invasive functional evaluation of coronary stenoses and subsequent planning of coronary revascularisation were beyond the scope of the current study and would require another cost-effectiveness analysis with that specific objective. 


\section{Clinical implications}

Our analysis shows cost-effectiveness of DSCT coronary angiography for diagnosing $\mathrm{CAD}$ in patients suspected as having this disease and those with an intermediate pretest likelihood for $\mathrm{CAD}$. One has to take into account though that pretest likelihood and prevalence do not necessarily mean the same thing. ${ }^{50}$ The global prevalence of CAD in our cohort is $24 \%$, which is still in agreement with a pretest likelihood at the lower end of intermediate risk. However, as an intermediate pretest likelihood generally ranges from $20 \%$ to $80 \%$, there may be situations in which the prevalence of $\mathrm{CAD}$ exceeds $55 \%$ and DSCT coronary angiography is no longer cost-effective. Thus, the most important step for physicians in selecting the appropriate diagnostic approach (DSCT vs invasive coronary angiography) is based on a clinical estimation of disease likelihood. The score by Morise et al provides an easy, memorable and accurate method for categorising and subcategorising patients with suspected $\mathrm{CAD}$ into probability groups upon which decisions concerning diagnostic testing could be based. ${ }^{21}$ Although invasive coronary angiography remains the gold standard for diagnosing CAD, carefully performed DSCT coronary angiography may be an economically efficient alternative to invasive angiography, especially in ruling out $\mathrm{CAD}$ in patients with an intermediate pretest likelihood.

Competing interests $\mathrm{MD}, \mathrm{CRB}$ and $\mathrm{AWL}$ have received consulting and lecture fees from Siemens Healthcare.

Ethics approval The present study is a cost-effectiveness analysis based on a previously elaborated patient cohort. Approval for this prior study was obtained from the Institutional Review Board of the University of Munich.

Contributors MD and $\mathrm{KB}$ were responsible for data collection, conducted literature searches, performed data analysis and drafted and critically revised the manuscript. CS conducted literature searches, participated in data collection and provided technical support. CRB and AWL were responsible for conception and design, critical revision of the manuscript and provision of supervision.

Provenance and peer review Not commissioned; externally peer reviewed.

\section{REFERENCES}

1. Lloyd-Jones D, Adams R, Carnethon M, et al. Heart disease and stroke statistics - 2009 update: a report from the American Heart Association Statistics Committee and Stroke Statistics Subcommittee. Circulation 2009;119:480-6.

2. Tardif JC. Coronary artery disease in 2010. Eur Heart J Supp/ 2010;12(Suppl C): C2-10.

3. Reddy KS. Cardiovascular disease in non-Western countries. N Engl J Med 2004:350:2438-40.

4. Allender S, Scarborough P, Peto V, et al. European cardiovascular disease statistics 2008. 3rd edn. Oxford: European Heart Network, 2008

5. Cassar A, Holmes DR, Rihal CS, et al. Chronic coronary artery disease: diagnosis and management. Mayo Clin Proc 2009;84:1130-46.

6. Mastouri R, Sawada SG, Mahenthiran J. Current noninvasive imaging techniques for detection of coronary artery disease. Expert Rev Cardiovasc Ther 2010;8:77-91.

7. Becker CR, Hong C, Knez A, et al. Optimal contrast application for cardiac 4detector-row computed tomography. Invest Radiol 2003:38:690-4.

8. Leber AW, Knez A, Becker A, et al. Accuracy of multidetector spiral computed tomography in identifying and differentiating the composition of coronary atherosclerotic plaques: a comparative study with intracoronary ultrasound. J Am Coll Cardiol 2004:43:1241-7.

9. Leber AW, Knez A, von Ziegler F, et al. Quantification of obstructive and nonobstructive coronary lesions by 64-slice computed tomography: a comparative study with quantitative coronary angiography and intravascular ultrasound. J Am Coll Cardiol 2005:46:147-54

10. De Graaf FR, Schuijf JD, van Velzen JE, et al. Diagnostic accuracy of 320-row multidetector computed tomography coronary angiography in the non-invasive evaluation of significant coronary artery disease. Eur Heart J 2010;31:1908-15.

11. Ropers U, Ropers D, Pflederer T, et al. Influence of heart rate on the diagnostic accuracy of dual-source computed tomography coronary angiography. J Am Coll Cardiol 2007;50:2393-8

12. Achenbach S, Ropers U, Kuettner A, et al. Randomized comparison of 64-slice single- and dual-source computed tomography coronary angiography for the detection of coronary artery disease. JACC Cardiovasc Imaging 2008;1:177-86.
13. Mollet NR, Cademartiri F, Nieman K, et al. Multislice spiral computed tomography coronary angiography in patients with stable angina pectoris. J Am Coll Cardiol 2004;43:2265-70.

14. Nieman K, Cademartiri F, Lemos PA, et al. Reliable noninvasive coronary angiography with fast submillimeter multislice spiral computed tomography. Circulation 2002:106:2051-4.

15. Raff GL, Gallagher MJ, O'Neill WW, et al. Diagnostic accuracy of noninvasive coronary angiography using 64-slice spiral computed tomography. J Am Coll Cardiol 2005:46:552-7.

16. Dewey $\mathbf{M}$, Hamm B. Cost effectiveness of coronary angiography and calcium scoring using CT and stress MRI for diagnosis of coronary artery disease. Eur Radiol 2007;17:1301-9.

17. Stacul F, Sironi D, Grisi G, et al. 64-Slice CT coronary angiography versus conventiona coronary angiography: activity-based cost analysis. Radiol Med 2009:114:239-52.

18. Fazel P, Peterman MA, Schussler JM. Three-year outcomes and cost analysis in patients receiving 64-slice computed tomographic coronary angiography for chest pain. Am J Cardiol 2009:104:498-500.

19. Halpern EJ, Savage MP, Fischman DL, et al. Cost-effectiveness of coronary CT angiography in evaluation of patients without symptoms who have positive stress test results. AJR Am J Roentgenol 2010:194:1257-62.

20. Leber AW, Johnson T, Becker A, et al. Diagnostic accuracy of dual-source multislice CT-coronary angiography in patients with an intermediate pretest likelihood of coronary artery disease. Eur Heart J 2007;28:2354-60.

21. Morise AP, Haddad WJ, Beckner D. Development and validation of a clinical score to estimate the probability of coronary artery disease in men and women presenting with suspected coronary disease. Am J Med 1997;102:350-6.

22. BroedI UC, Lebherz C, Lehrke M, et al. Low adiponectin levels are an independent predictor of mixed and non-calcified coronary atherosclerotic plaques. PLoS One 2009; 4:e4733.

23. Dodge JT, Brown BG, Bolson EL, et al. Intrathoracic spatial location of specified coronary segments on the normal human heart. Applications in quantitative arteriography, assessment of regional risk and contraction, and anatomic display. Circulation 1988;78:1167-80.

24. Hamm CW, Albrecht A, Bonzel T, et al. Diagnostic heart catheterization. Clin Res Cardiol 2008;97:475-512.

25. McNeil BJ, Varady PD, Burrows BA, et al. Measures of clinical efficacy: costeffectiveness calculations in the diagnosis and treatment of hypertensive renovascular disease. N Engl J Med 1975;293:216-21.

26. Patterson RE, Eisner RL, Horowitz SF. Comparison of cost-effectiveness and utility of exercise ECG, single photon emission computed tomography, positron emission tomography, and coronary angiography for diagnosis of coronary artery disease. Circulation 1995;91:54-65.

27. Patterson RE, Eng C, Horowitz SF, et al. Bayesian comparison of cost-effectiveness of different clinical approaches to diagnose coronary artery disease. J Am Coll Cardio 1984:4:278-89.

28. Tiemann 0. Variations in hospitalisation costs for acute myocardial infarction-a comparison across Europe. Health Econ 2008;17:S33-45.

29. Brüggenjürgen $\mathbf{B}$, Lindgren $P$, Ehlken $B$, et al. Long-term cost-effectiveness of clopidogrel in patients with acute coronary syndrome without ST-segment elevation in Germany. Eur J Health Econ 2007:8:51-7.

30. Ray JA, Valentine WJ, Secnik K, et al. Review of the cost of diabetes complications in Australia, Canada, France, Germany, Italy and Spain. Curr Med Res Opin 2005;21:1617-29.

31. Katayama H, Yamaguchi K, Kozuka T, et al. Adverse reactions to ionic and nonionic contrast media. A report from the Japanese Committee on the Safety of Contrast Media. Radiology 1990;175:621-8.

32. Sohns C, Sossalla S, Vollmann D, et al. Extra cardiac findings by 64-multidetector computed tomography in patients with symptomatic atrial fibrillation prior to pulmonal vein isolation. Int J Cardiovasc Imaging 2011;27:127-34.

33. Singer ME, Applegate KE. Cost-effectiveness analysis in radiology. Radiology 2001:219:611-20.

34. Neumann PJ, Rosen AB, Weinstein MC. Medicare and cost-effectiveness analysis N Engl J Med 2005;353:1516-22

35. Otero HJ, Rybicki FJ, Greenberg D, et al. Cost-effective diagnostic cardiovascular imaging: when does it provide good value for the money? Int J Cardiovasc Imaging 2010;26:605-12

36. Cohen MD, Hawes DR, Hutchins GD, et al. Activity-based cost analysis: a method of analyzing the financial and operating performance of academic radiology departments. Radiology 2000;215:708-16.

37. Eagle KA, Knight BP, Moscucci M, et al. Competitive bidding for interventional cardiology supplies: lessons learned during round 2. Am J Manag Care 2002; 8:384-8.

38. Robinson R. Cost-benefit analysis. BMJ 1993;307:924-6.

39. Tsiflikas I, Brodoefel H, Reimann AJ, et al. Coronary CT angiography with dual source computed tomography in 170 patients. Eur J Radiol 2010;74:161-5.

40. Weustink AC, Neefjes LA, Kyrzopoulos S, et al. Impact of heart rate frequency and variability on radiation exposure, image quality, and diagnostic performance in dualsource spiral CT coronary angiography. Radiology 2009;253:672-80.

41. Van Werkhoven JM, Gaemperli 0, Schuijf JD, et al. Multislice computed tomography coronary angiography for risk stratification in patients with an intermediate pretest likelihood. Heart 2009;95:1607-11. 
42. Van Werkhoven JM, Heijenbrok MW, Schuijf JD, et al. Combined non-invasive anatomical and functional assessment with MSCT and MRI for the detection of significant coronary artery disease in patients with an intermediate pre-test likelihood. Heart 2010:96:425-31.

43. Donnino R, Jacobs JE, Doshi JV, et al. Dual-source versus single-source cardiac CT angiography: comparison of diagnostic image quality. AJR Am J Roentgenol 2009:192:1051-6

44. Baumüller S, Leschka S, Desbiolles L, et al. Dual-source versus 64-section CT coronary angiography at lower heart rates: comparison of accuracy and radiation dose. Radiology 2009;253:56-64.

45. Meijboom WB, van Mieghem CA, Mollet NR, et al. 64-Slice computed tomography coronary angiography in patients with high, intermediate, or low pretest probability of significant coronary artery disease. J Am Coll Cardiol 2007;50:1469-75.

46. Hendel RC, Patel MR, Kramer CM, et al. ACCF/ACR/SCCT/SCMR/ASNC/NASCI/ SCAl/SIR 2006 appropriateness criteria for cardiac computed tomography and cardiac magnetic resonance imaging: a report of the American College of Cardiology
Foundation Quality Strategic Directions Committee Appropriateness Criteria Working Group, American College of Radiology, Society of Cardiovascular Computed Tomography, Society for Cardiovascular Magnetic Resonance, American Society of Nuclear Cardiology, North American Society for Cardiac Imaging, Society for Cardiovascular Angiography and Interventions, and Society of Interventional Radiology. J Am Coll Cardiol 2006:48:1475-97.

47. Weustink AC, Mollet NR, Neefjes LA, et al. Diagnostic accuracy and clinical utility of noninvasive testing for coronary artery disease. Ann Intern Med 2010;152:630-9.

48. Bastarrika G, Shyan Y, Huda W, et al. CT of coronary artery disease. Radiology 2009;253:317-38.

49. Skinner JS, Smeeth L, Kendall JM, et al. on behalf of the Chest Pain Guideline Development Group. NICE guidance. Chest pain of recent onset: assessment and diagnosis of recent onset chest pain or discomfort of suspected cardiac origin. Heart 2010;96:974-8.

50. Le Guludec D, Sarda L. "Prevalence" or "pretest likelihood" of coronary artery disease? J Am Coll Cardiol 1997;29:225-6.

\section{DIFFERENTIAL DIAGNOSIS}

\section{Trustworthy guidance on your iPhone}

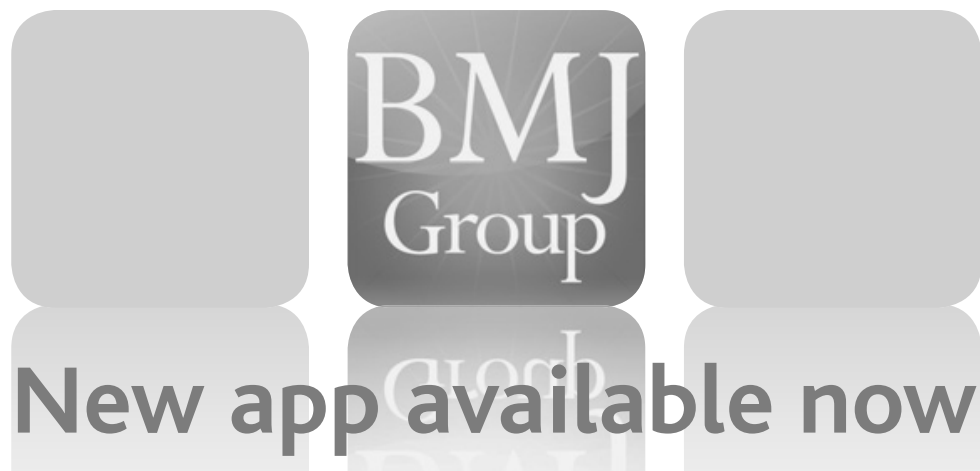

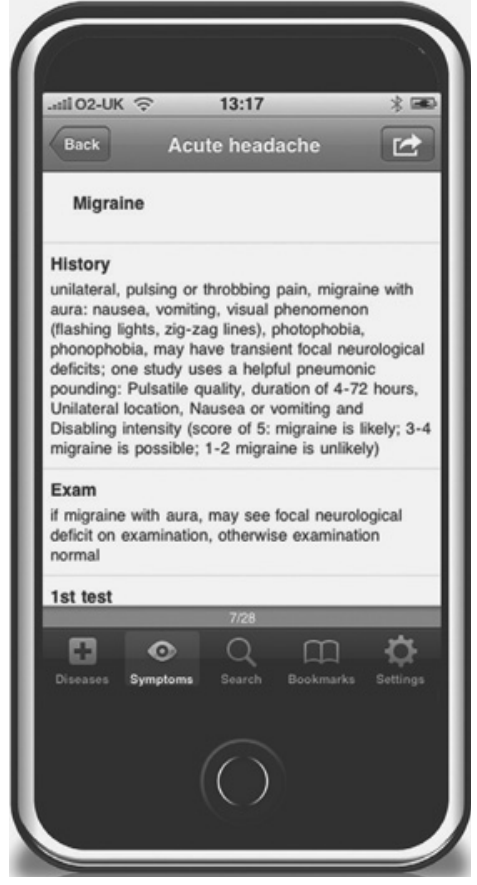

\section{Find out more at bestpractice.bmj.com/differentials}




\section{Heart}

\section{Direct costs and cost-effectiveness of dual-source computed tomography and invasive coronary angiography in patients with an intermediate pretest likelihood for coronary artery disease}

Marc Dorenkamp, Klaus Bonaventura, Christian Sohns, Christoph R Becker and Alexander W Leber

Heart 2012 98: 460-467 originally published online August 16, 2011 doi: 10.1136/heartjnl-2011-300149

Updated information and services can be found at:

http://heart.bmj.com/content/98/6/460

These include:

References This article cites 49 articles, 11 of which you can access for free at: http://heart.bmj.com/content/98/6/460\#BIBL

Email alerting Receive free email alerts when new articles cite this article. Sign up in the service box at the top right corner of the online article.

Topic Articles on similar topics can be found in the following collections

Collections

Drugs: cardiovascular system (7925)

\section{Notes}

To request permissions go to:

http://group.bmj.com/group/rights-licensing/permissions

To order reprints go to:

http://journals.bmj.com/cgi/reprintform

To subscribe to BMJ go to:

http://group.bmj.com/subscribe/ 